\title{
Nucleolar stress regulation of endometrial receptivity in mouse models and human cell lines
}

\author{
Wei Hu', Yu-Xiang Liang ${ }^{1,2,3}$, Jia-Mei Luo', Xiao-Wei Gu', Zi-Cong Chen'1, Tao Fu', Yu-Yuan Zhu', Shuai Lin', \\ Hong-Lu Diao ${ }^{4}$, Bo Jia ${ }^{5}$ and Zeng-Ming Yang ${ }^{1}$
}

\begin{abstract}
Embryo implantation is essential to the successful establishment of pregnancy. A previous study has demonstrated that actinomycin D (ActD) could initiate the activation of mouse delayed implantation. However, the mechanism underlying this activation remains to be elucidated. A low dose of ActD is an inducer of nucleolar stress. This study was to examine whether nucleolar stress is involved in embryo implantation. We showed that nucleolar stress occurred when delayed implantation was activated by ActD in mice. ActD treatment also stimulated the Lif-STAT3 pathway. During early pregnancy, nucleolar stress was detected in the luminal epithelial cells during the receptive phase. Blastocyst-derived lactate could induce nucleolar stress in cultured luminal epithelial cells. The inhibition of nucleophosmin1 (NPM1), which was a marker of nucleolar stress, compromised uterine receptivity and decreased the implantation rates in pregnant mice. To translate these mouse data into humans, we examined nucleolar stress in human endometrium. Our data demonstrated that ActD-induced nucleolar stress had positive effects on the embryo attachment by upregulating IL32 expression in non-receptive epithelial cells rather than receptive epithelial cells. Our data should be the first to demonstrate that nucleolar stress is present during early pregnancy and is able to induce embryo implantation in both mice and humans.
\end{abstract}

\section{Introduction}

The cross-talk between the blastocyst with implantation competency and the receptive endometrium is critical for successful implantation ${ }^{1-3}$. Embryo implantation is a ratelimiting step for successful pregnancy. In humans, 15\% of couples are infertile. The failure of embryo implantation is the main cause of early pregnancy $\operatorname{loss}^{1}$.

Nucleolus, a distinct membrane-less subnuclear compartment, contains three morphologically distinct subcompartments: the fibrillar center, the dense fibrillar component, and the peripheral granular component ${ }^{4}$.

\footnotetext{
Correspondence: Zeng-Ming Yang (zmyang@scau.edu.cn)

${ }^{1}$ College of Veterinary Medicine, South China Agricultural University, 510642

Guangzhou, China

${ }^{2}$ Laboratory Animal Center, Shanxi Key Laboratory of Experimental Animal

Science and Animal Model of Human Disease, Shanxi Medical University, 030001 Taiyuan, China

Full list of author information is available at the end of the article.

These authos contributed equally: Wei Hu, Yu-Xiang Liang

Edited by $Y$. Shi
}

Nucleolus is primarily associated with ribosome biogenesis, the regulation of mitosis, cell-cycle progression, proliferation, and stress responses ${ }^{5}$. Nucleolar stress is the failure of ribosome biogenesis or the failure of a function that ultimately leads to a disturbed homeostasis ${ }^{4}$. Nucleolar stress can be used to monitor the synthesis and assembly of rRNAs and ribosome proteins, and can be induced by ActD, 5-FU, CX5461, nutrient deprivation, or ultraviolet radiation ${ }^{6,7}$. NPM1 is localized in the nucleolus under normal conditions ${ }^{8-11}$. Once nucleolar stress occurs, NPM1 relocates from the nucleolus to the nucleoplasm, where it can combine with Mdm2 (known as HDM2 in human) to prevent p53 from the ubiquitination degradation by $\mathrm{Mdm} 2$ and cause the accumulation of $\mathrm{p} 53^{8,11}$. The roles of nucleolar stress in cancer cells have attracted significant attention ${ }^{7,12}$. However, the potential physiological functions of nucleolar stress remain largely unexplored.

\section{(c) The Author(s) 2019}

(c) Open Access This article is licensed under a Creative Commons Attribution 4.0 International License, which permits use, sharing, adaptation, distribution and reproduction cc) in any medium or format, as long as you give appropriate credit to the original author(s) and the source, provide a link to the Creative Commons license, and indicate if changes were made. The images or other third party material in this article are included in the article's Creative Commons license, unless indicated otherwise in a credit line to the material. If material is not included in the article's Creative Commons license and your intended use is not permitted by statutory regulation or exceeds the permitted use, you will need to obtain permission directly from the copyright holder. To view a copy of this license, visit http://creativecommons.org/licenses/by/4.0/. 
The establishment of uterine receptivity is a key step for successful pregnancy ${ }^{1,2}$. Both LIF and Stat3 are essential to mouse blastocyst implantation ${ }^{13-15}$. p53 also plays an important role during embryo implantation via regulating LIF $^{16}$. Under nucleolar stress, p53 accumulation is significantly enhanced ${ }^{17}$. It has been shown that ActD treatment is able to initiate the activation of delayed implantation in mice and rats ${ }^{18,19}$. Otherwise, embryo implantation process is accompanied by increased endometrial vascular permeability, cell damage and inflammatory response including IL-6, IL-1, and $\mathrm{LIF}^{20}$. Therefore, it is reasonable that there may exist some cell stress responses which may be essential during embryo implantation process. We hypothesized that nucleolar stress should play a key role during embryo implantation.

Our results show that nucleolar stress occurs during the receptive phase of early pregnancy and that the LifSTAT3 signaling pathway is activated by nucleolar stress that is induced by blastocyst-derived lactate. NPM1 inhibition compromises mouse embryo implantation. Our data also showed that nucleolar stress in human nonreceptive epithelial, but not receptive epithelial, could improve the attachment rates of Jeg- 3 spheroids through increasing IL32 secretion.

\section{Materials and methods}

\section{Animals and treatments}

Mature CD1 mice were obtained from Hunan Slack Laboratory Animal Co., LTD and were maintained under a specific pathogen-free (SPF) and controlled environment (cycles of $12 \mathrm{~h}$ of light and $12 \mathrm{~h}$ of dark). All animal procedures were approved by the Animal Care and Use Committee of South China Agricultural University. Pregnant or pseudopregnant female mice (8-10 weeks) were obtained by mating with fertile or vasectomized males of the same strain (day 1 is the day of the vaginal plug). From days 1 through 4, the embryos were flushed from the oviducts or uteri to determine whether the mice were successfully pregnant. The implantation sites on day 5 were confirmed by a tail intravenous injection of Chicago blue dye (Sigma-Aldrich, USA). Artificial decidualization was performed as previously described ${ }^{21,22}$.

On day 4 ( $0800 \mathrm{~h}$ to $0900 \mathrm{~h}$ ) of pregnancy, the mice were ovariectomized to induce delayed implantation. Delayed implantation was maintained by the daily injection of progesterone $(1 \mathrm{mg} / 0.1 \mathrm{ml}$ sesame oil/mouse, SigmaAldrich) from days 5 to 9 . On day 7, the mice were intraperitoneally injected with ActD $(27.5 \mu \mathrm{g} /$ mouse (27.5 $\mu$ g ActD dissolved in 2.191 $\mu \mathrm{l}$ DMSO and $97.809 \mu \mathrm{l}$ saline), Abcam, UK). The injection of an equal solvent served as a control. The mice were killed at different time points after the injection to collect the uteri for further analyses.
To examine the effects of NPM1 on embryonic implantation, the mice were intraperitoneally injected with the NPM1-specific antagonist NSC348884 $(80 \mu \mathrm{g} /$ mouse and $160 \mu \mathrm{g} / \mathrm{mouse}$ in saline; $31.85 \mathrm{mg} / \mathrm{ml}$ dissolved in DMSO and diluted in saline, $100 \mu \mathrm{l}$ per mouse, Selleckchem, USA) from days 4 to 5 of pregnancy. The injection of an equal solvent served as a control. On day 6 , the implantation sites were confirmed by a tail intravenous injection of Chicago blue dye. To analyze the effects of NPM1 on the implantation-related markers, NSC348884 was injected on day 3 of pregnancy. The uteri were collected $24 \mathrm{~h}$ after NSC348884 injection.

\section{Isolation and treatment of uterine luminal epithelial cells}

The luminal epithelial cells were isolated as previously described $^{23}$. Briefly, to obtain the luminal epithelial cells, the uteri were digested with sterile HBSS containing $0.3 \%$ trypsin and $6 \mathrm{mg} / \mathrm{ml}$ dispase for $1.5 \mathrm{~h}$ at $4{ }^{\circ} \mathrm{C}$ followed by $30 \mathrm{~min}$ at room temperature and $10 \mathrm{~min}$ at $37^{\circ} \mathrm{C}$. The luminal epithelial cells were cultured in DMEM/F-12 medium (Sigma-Aldrich) containing 10\% heat-inactivated fetal bovine serum (FBS, Invitrogen, USA). For in vitro treatment, the luminal epithelial cells were treated with associated reagents.

\section{Human cell lines and in vitro embryo attachment assay}

Ishikawa (Human endometrial epithelial cells), Jeg-3 (HTB-36), and AN3 CA (Human endometrial epithelial cells) cells were purchased from American Type Culture Collection (ATCC, USA). The embryo attachment in vitro model was constructed as described previously with minor modifications ${ }^{24}$. Briefly, Ishikawa and Jeg-3 were cultured in DMEM/F-12 medium containing 10\% FBS. AN3 CA were cultured in MEM (Eagle) medium (SigmaAldrich) supplemented with 10\% FBS and L-Glu. The Ishikawa cells or AN3 CA cells were seeded at $2 \times 10^{5}$ cells per well in 12-well plate. The Jeg-3 cells at about $90 \%$ confluency were trypsinized, washed and seeded $\left(2.5 \times 10^{5}\right.$ cells per well) in a 6-well plate and shaken at $84 \mathrm{rpm}$ overnight for spheroid generation. After treatment by ActD $10 \mathrm{nM}$ or recombinant human IL32 (Bio Vision, USA) $10 \mathrm{ng} / \mathrm{mL}$ and $100 \mathrm{ng} / \mathrm{mL}$ for $48 \mathrm{~h}$, the wells containing the Ishikawa cells were washed with PBS and refilled with fresh DMEM/F-12 containing 1\% bovine serum albumin (BSA, Sigma-Aldrich). Jeg-3 spheroids with diameter of $100-200 \mu \mathrm{m}$ were selected and 30 spheroids were gently added onto Ishikawa monolayer with a glass pipette under microscopic visualization per well. The co-culture was maintained for $1 \mathrm{~h}$ at $37^{\circ} \mathrm{C}$ under $5 \% \mathrm{CO}_{2}$ in air and then subjected to vigorous shaking at $140 \mathrm{rpm}$ for $10 \mathrm{~min}$. The medium was removed and refilled. The number of attached spheroids was counted under microscope. Attachment rate was defined as the 
ratio of the number of attached spheroids to the total number of spheroids seeded.

\section{Human endometrium sample collection}

For experiments examining expression patterns of NPM1, we used samples of human endometrium from health women between the age of 18 and 45 with regular cycles. All human procedures were approved by the Institutional Committee on the Use of Human Subjects in Hubei University of Medicine. Written informed consent was obtained from all participating subjects that donated endometrial biopsies. Histologic dating of endometrial samples was done on the basis of the criteria of Noyes, and confirmed by subsequent histopathological examination.

\section{Transfer of ActD-soaked beads}

The injections of ActD-soaked beads were performed as previously described ${ }^{25,26}$. Briefly, Affi-Gel Blue Gel Beads (\#1537301, Bio-Rad, USA), which were approximately the size of a blastocyst, were washed three times with sterile Hanks' balanced salt solution (HBSS, Sigma-Aldrich) and were then incubated with ActD $(1 \mathrm{mM})$ in $30 \mu \mathrm{l} 0.4 \%$ PVA (Sigma-Aldrich) at $37^{\circ} \mathrm{C}$ for $3 \mathrm{~h}$. Loaded beads (eight beads/ horn) were transferred into the uterine lumen of day 4 pseudopregnant mice. The mice were killed at day 6 after Chicago blue dye injection. The uteri with blue bands were collected for further analyses.

\section{In situ hybridization}

The cDNA fragment of each target gene was amplified with specific PCR primers (Table 1) and was cloned into pGEM-T easy vector (Promega, USA). After ensuring the direction of each insert in the vectors, the antisense or sense cRNA probes were labeled with the Digoxigenin RNA Labeling Kit (Roche Applied Science, USA).

In situ hybridization was performed as described previously $^{25,27}$. Frozen sections $(10 \mu \mathrm{m})$ were fixed with a $4 \%$ paraformaldehyde solution in PBS and were hybridized overnight at $55^{\circ} \mathrm{C}$. Following the post-hybridization washes, the sections were incubated with a sheep antidigoxigenin antibody conjugated to alkaline phosphatase at $4{ }^{\circ} \mathrm{C}$ overnight (1:5000; Roche). Finally, the signals were visualized with nitroblue tetrazolium (NBT, $0.4 \mathrm{mM})$ and 5-bromo-4-chloro-3-indolyl phosphate (BCIP, $0.4 \mathrm{mM}$ ). All sections were counterstained with $1 \%$ methyl green.

\section{Immunohistochemistry}

Immunohistochemistry was performed as previously described $^{28}$. The paraffin sections $(5 \mu \mathrm{m})$ were deparaffinized in xylene, rehydrated with a graded series of ethanol, and washed in water. Antigen retrieval was performed by microwaving the sections in $10 \mathrm{mM}$ sodium citrate buffer ( $\mathrm{pH}$ 6.0) followed by cooling the sections to room temperature. The endogenous horse radish peroxidase activity was inhibited with $3 \% \mathrm{H}_{2} \mathrm{O}_{2}$ for $15 \mathrm{~min}$. After nonspecific binding was blocked with $10 \%$ horse serum at $37^{\circ} \mathrm{C}$ for $1 \mathrm{~h}$, the sections were incubated with a rabbit anti-p-Stat3 antibody (\#9145, 1:400, Cell Signaling, USA) at $4{ }^{\circ} \mathrm{C}$ overnight. The sections were then incubated with a biotin-labeled goat anti-rabbit IgG antibody and a streptavidin-conjugated HRP complex (Zhongshan Golden Bridge, China). Finally, the signals were visualized with the DAB Horseradish Peroxidase Color Development Kit. The sections were counterstained with hematoxylin.

\section{Real-time PCR}

The total RNA was isolated using the TRIzol Reagent Kit (Invitrogen), digested with RQ1 deoxyribonuclease I (Promega, Fitchburg, WI), and reverse-transcribed into cDNA with the PrimeScript Reverse Transcriptase Reagent Kit (TaKaRa, Japan). For real-time PCR, the cDNA was amplified using a SYBR Premix Ex Taq Kit (TaKaRa) on the CFX96 Touch $^{\mathrm{TM}}$ Real-Time System (BioRad). The data from real-time PCR were analyzed using the $2^{-\Delta \Delta \mathrm{Ct}}$ method. The relative expression levels were normalized to the expression level of $\mathrm{Rpl}$ (mouse) or RPL7 (human).

\section{Western blot}

Western blot was performed as previously described $^{21,22}$. Briefly, the tissues or cells were lysed in lysis buffer $(150 \mathrm{mM} \mathrm{NaCl} ; 50 \mathrm{mM}$ Tris- $\mathrm{HCl}, \mathrm{pH} 7.5 ; 1 \%$ Triton X-100; and $0.25 \%$ sodium deoxycholate). The protein concentrations were measured with the BCA Kit (Thermo Fisher). The protein samples were separated on $10 \%$ SDSPAGE gels and were transferred onto PVDF membranes. The membranes were incubated with primary antibody overnight at $4{ }^{\circ} \mathrm{C}$. The primary antibodies used in this study include anti-phospho-Stat3 (\#9145, 1:1000, Cell Signaling), anti-p53 (\#2524, 1:1000, Cell Signaling), antiCytokeratin18 (\#6259, 1:1000, Santa Cruz, USA), antiVimentin (\#3932, 1:1000, Cell Signaling), anti-Tubulin (\#2144, 1:1000, Cell Signaling), anti- $\beta$-Actin (\#4970, 1:1000, Cell Signaling) and anti-GAPDH (\#25778, 1:2000, Santa Cruz). After the membranes were incubated with an HRP-conjugated secondary antibody (1:5000) for $1 \mathrm{~h}$, the signals were detected with an ECL Chemiluminescent Kit (Millipore, USA).

\section{Immunofluorescence}

Immunofluorescence was performed as previously described with some modifications ${ }^{21,22}$. After the paraffin sections $(5 \mu \mathrm{m})$ were deparaffinized and rehydrated, antigen retrieval was performed by microwaving the sections in $10 \mathrm{mM}$ sodium citrate buffer (pH 6.0). Nonspecific binding was blocked with $3 \%$ BSA. The sections 
Table 1 Primers used in this study

\begin{tabular}{|c|c|c|c|c|}
\hline Gene & Primers $\left(5^{\prime}-3^{\prime}\right)$ & ID & Products (bp) & Application \\
\hline Rpl7 & $\begin{array}{l}\text { GCAGATGTACCGCACTGAGATTC } \\
\text { ACCTTGGGCTTACTCCATTGATA }\end{array}$ & NM_29016 & 129 & RT-PCR \\
\hline Its 1 & $\begin{array}{l}\text { TCCGTGTCTACGAGGGGCGG } \\
\text { GGGTGCCGGGAGAGCAAAGC }\end{array}$ & XR_877120.2 & 95 & RT-PCR \\
\hline$p 21$ & $\begin{array}{l}\text { TGAGCGGCCTGAAGATTCC } \\
\text { TCTGC }\end{array}$ & NM_007669.5 & 82 & RT-PCR \\
\hline Mdm2 & $\begin{array}{l}\text { AATTTAGTGGCTGTAAGTCAGCAAGA } \\
\text { ATCCTTCAGATCACTCCCACCTT }\end{array}$ & NM_010786.4 & 87 & RT-PCR \\
\hline Lif & $\begin{array}{l}\text { AAAAGCTATGTGCGCCTAACA } \\
\text { GTATGCGACCATCCGATACAG }\end{array}$ & NM_008501 & 98 & RT-PCR \\
\hline p53 & $\begin{array}{l}\text { GCAGTTGTGGGTCAGC } \\
\text { ATCACCATCGGAGCAG }\end{array}$ & NM_011640 & 130 & RT-PCR \\
\hline RPL7 & CTGCTGTGCCAGAAACCCTT TCTTGCCATCCTCGCCAT & NM_000971 & 194 & RT-PCR \\
\hline IL32 & $\begin{array}{l}\text { GACTTCAAAGAGGGCTACC } \\
\text { GGCACCGTAATCCATCTC }\end{array}$ & NM_001012631.1 & 103 & RT-PCR \\
\hline ITS1 & $\begin{array}{l}\text { TGTCAGGCGTTCTCGTCTC } \\
\text { GAGAGCACGACGTCACCAC }\end{array}$ & NR_046235.1 & 146 & RT-PCR \\
\hline Npm1 & $\begin{array}{l}\text { AGCACCAGTTGTCATTAAGA } \\
\text { CTCATCATCGTCCTCATCAT }\end{array}$ & NM_001252260.1 & 386 & ISH \\
\hline Ptgs2 & $\begin{array}{l}\text { TGGCTTCGGGAGCACAAC } \\
\text { GCCTTTGCCACTGCTTGT }\end{array}$ & NM_011198 & 437 & ISH \\
\hline Wnt4 & $\begin{array}{l}\text { GGAGACGTGCGAGAAACTCA } \\
\text { TGTTGTCCGAGCATCCTGAC }\end{array}$ & NM_009523.2 & 356 & ISH \\
\hline Egr1 & $\begin{array}{l}\text { CCCATGATCCCTGACTATCT } \\
\text { CAAACTTCCTCCCACAAAT }\end{array}$ & NM_007913 & 469 & ISH \\
\hline
\end{tabular}

were incubated with a rabbit anti-NPM1 antibody (\#10306, Proteintech, USA) in blocking solution overnight at $4{ }^{\circ} \mathrm{C}$; then, the sections were incubated with an FITCconjugated secondary antibody for $40 \mathrm{~min}$. Finally, the sections were counterstained with 4'6-diamidino-2-phenylindole dihydrochloride (DAPI) or propidium iodide (PI) and were mounted with ProLong ${ }^{\mathrm{TM}}$ Diamond Antifade Mountant (Thermo Fisher, USA). The pictures were captured by laser scanning confocal microscopy (Leica, Germany).

\section{Lactate assay}

The blastocysts were collected from uteri of pregnancy mice on day 4 and were cultured in the $25 \mu \mathrm{l} 2 \%$ FBS culture medium, each drop contains 20 embryos. After $48 \mathrm{~h}$, the lactate concentration of medium was assayed by L-Lactate Assay Kit (Cayman, USA) according to the manufacturer's instructions. The assay was detected using a fluorescence spectrophotometer at excitation wavelength 530-540 $\mathrm{nm}$ and emission wavelength 585-595 nm.

\section{Statistical analysis}

All of the experiments were repeated independently at least three times. For mouse studies, at least three mice were included in each group. The data were presented as the mean \pm standard deviation (SD). The differences between the two groups were compared by Student's $t$ test. A $P$ value $<0.05$ was considered statistically significant.

\section{Results}

\section{ActD activation of delayed implantation via nucleolar stress}

Previous studies showed that the delayed implantation of mice and rats could be activated by ActD $^{18,19}$. ActD is a selective inhibitor of polymerase I transcription and an inducer of nucleolar stress ${ }^{6}$. Therefore, we assumed that nucleolar stress may be involved during embryo implantation. To explore whether delayed implantation was activated by ActD, the mice with delayed implantation were treated with ActD on day 7. Compared to those of 
A

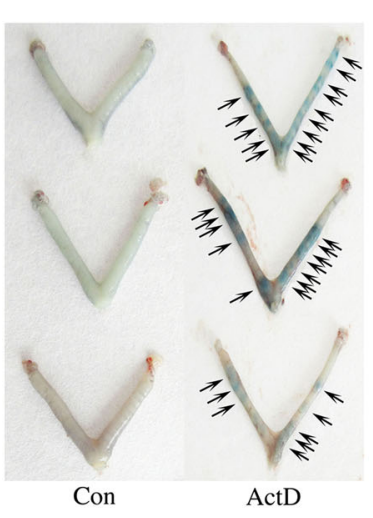

C

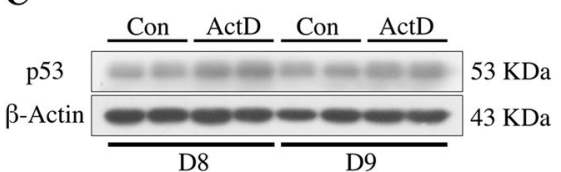

\section{D}

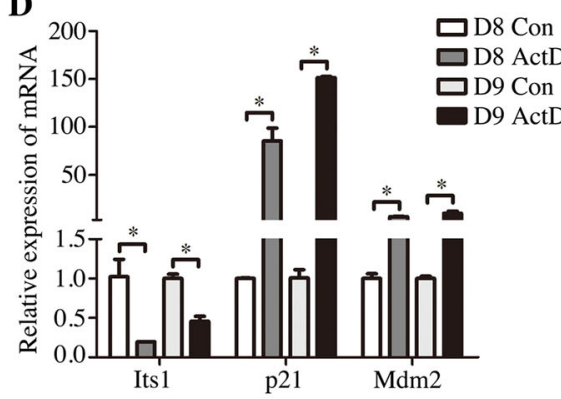

F

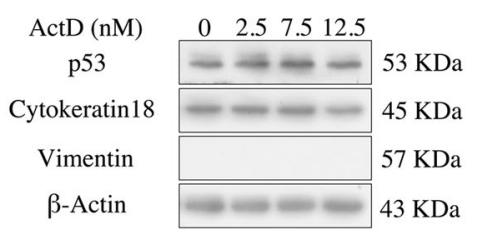

B

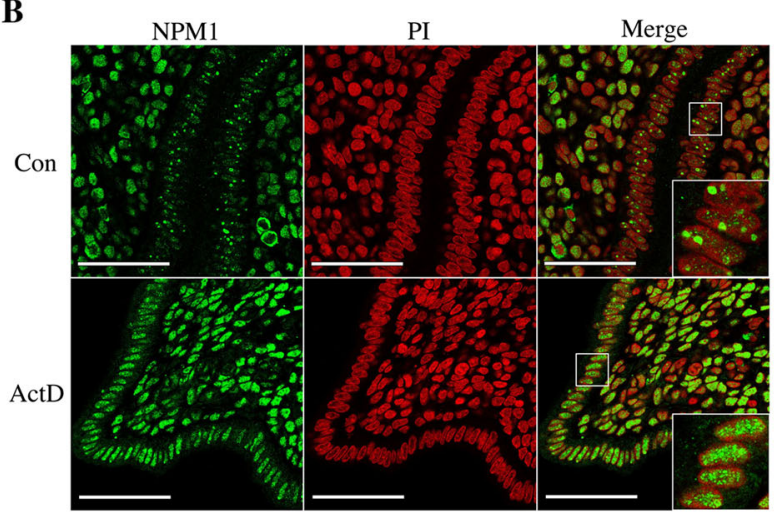

$\mathbf{E}$

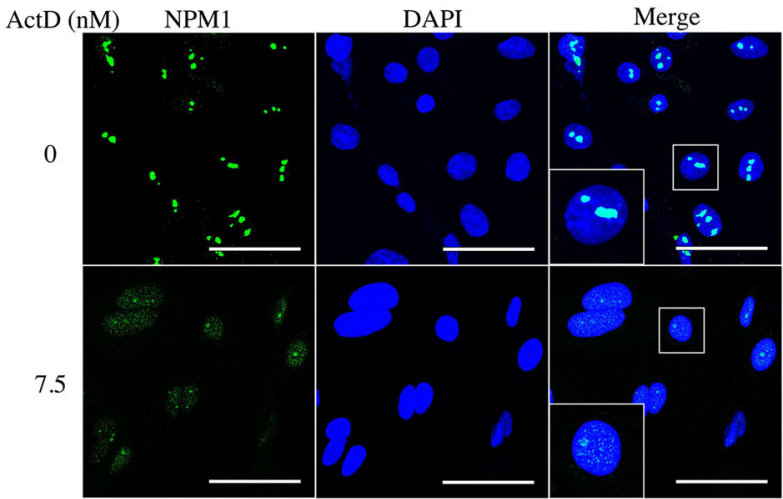

G

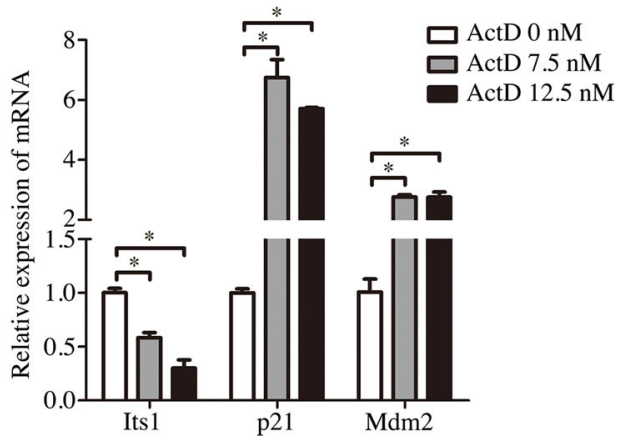

Fig. 1 The effects of ActD-induced nucleolar stress on embryo implantation. a Delayed embryo implantation is activated by ActD at a dosage of $27.5 \mathrm{\mu g} /$ mouse. $\mathbf{b}$ Immunofluorescence was used to indicate the location of NPM1 in the control and ActD-treated mouse uterus. Bar $=50 \mu \mathrm{m}$. $\mathbf{c}$ Western blot of the p53 protein in mouse uteri on days 8 and 9 (D8, mouse treated with vehicle or ActD for 1 day; D9, mouse treated with vehicle or ActD for 2 days). $\beta$-Actin was used as a loading control. $\mathbf{d}$ Real-time PCR analysis of the Its1, p21 and Mdm2 mRNA levels in mouse uteri on days 8 and 9. e The location of NPM1 in the luminal epithelial cells treated with ActD for $12 \mathrm{~h}$. Bar $=25 \mu \mathrm{m}$. $\mathbf{f}$ Western blot of the p53 protein in ActD-treated luminal epithelial cells. Cytokeratin 18 was used as a marker of luminal epithelium. Vimentin was used as a marker of stromal cells. $\beta$-Actin was used as a loading control. $\mathbf{g}$ Real-time PCR analysis of the Its1, p21 and Mdm2 mRNA levels in the ActD-treated luminal epithelial cells. Data are presented as the mean $\pm S D,{ }^{*} p<0.05$

the control group, implantation sites were clearly observed in the ActD-treated group (Fig. 1a). In ActDtreated mice, NPM1, a marker of nucleolar stress, was relocated from the nucleolus to the nucleoplasm in the endometrial luminal epithelial cells on days 8 and 9 (Fig. 1b). Western blot analyses showed that p53 was upregulated in the ActD-treated uteri (Fig. 1c). Additional markers of nucleolar stress were also noted in these samples ${ }^{17}$. In the ActD-treated uteri, pre-rRNA (Its1) was downregulated, while p21 and $\mathrm{Mdm} 2$, the p53 target genes, were upregulated (Fig. 1d). These results suggested that nucleolar stress takes place in the ActD-treated uteri. When cultured luminal epithelial cells were treated with 2.5, 7.5, and $12.5 \mathrm{nM}$ ActD, NPM1 was relocated from the 
A

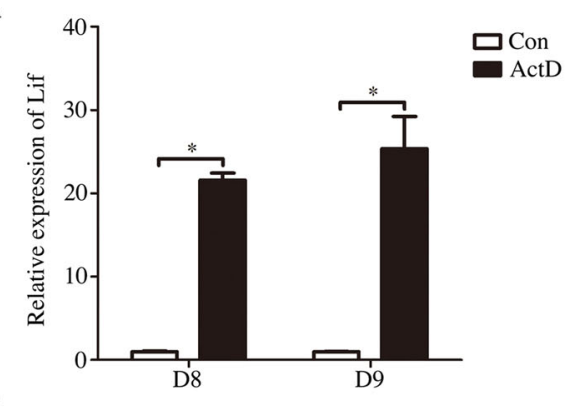

C

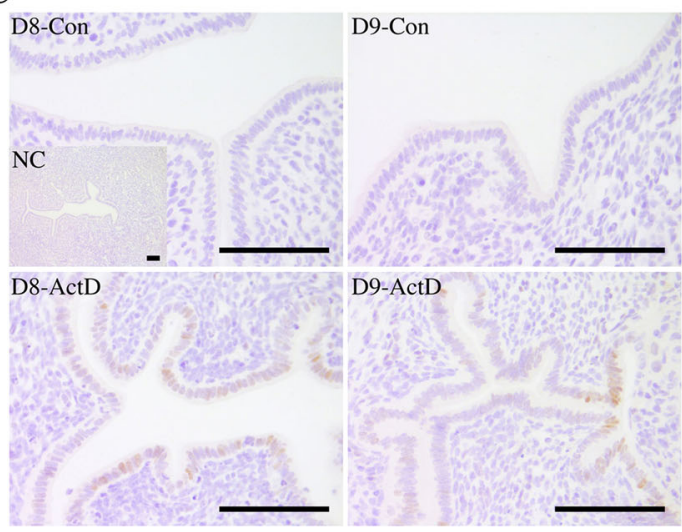

B

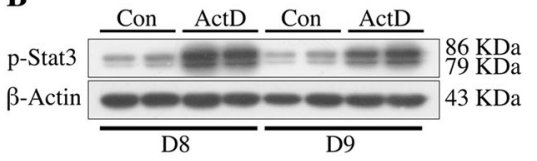

D

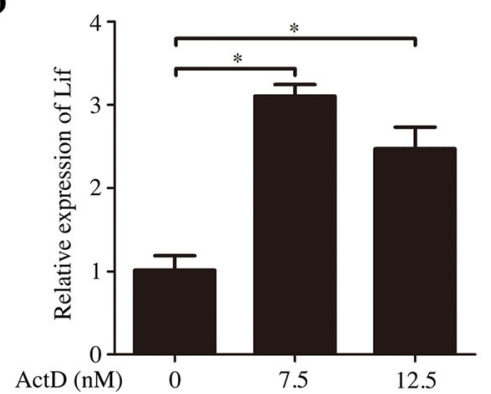

$\mathbf{E}$

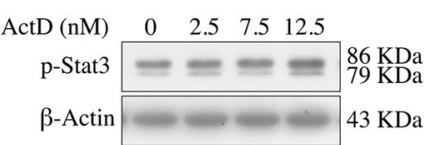

Fig. 2 Effects of nucleolar stress on Lif and p-Stat3 levels after delayed implantation were activated by ActD. a Real-time PCR analysis of the Lif mRNA level in mouse uteri on days 8 and 9 (D8, mouse treated with vehicle or ActD for 1 day; D9, mouse treated with vehicle or ActD for 2 days). b Western blot of the p-Stat3 protein in mouse uteri on days 8 and 9. $\beta$-Actin was used as a loading control. c Immunohistochemical staining showing p-Stat3 immunostaining in mouse uteri on days 8 and 9. Bar $=100 \mu \mathrm{m}$. $\mathbf{d}$ Real-time PCR analysis of the Lif mRNA level in the luminal epithelial cells treated with ActD for $12 \mathrm{~h}$. e Western blot of the p-Stat3 protein in luminal epithelial cells treated with ActD for $1 \mathrm{~h}$. $\beta$-Actin was used as a loading control. Data are presented as the mean $\pm \mathrm{SD},{ }^{*} p<0.05$

nucleolus to the nucleoplasm after ActD treatment for $12 \mathrm{~h}$ (Fig. 1e). In these ActD-treated cells, there were an increase in the levels of p53, p21 and Mdm2 (Fig. 1f, g) and a decrease in Its1 (Fig. 1g). Overall, these data indicated that ActD could induce nucleolar stress in luminal epithelial cells.

\section{Effects of nucleolar stress on the Lif-STAT3 pathway}

Lif and its downstream target Stat3 are required for mouse embryo implantation ${ }^{13,14}$. When the mice under delayed implantation were treated with ActD on day 7, Lif expression was significantly increased in these ActDtreated uteri on days 8 and 9 (Fig. 2a). In these ActDtreated mouse uteri, the $\mathrm{p}$-Stat3 level was also upregulated (Fig. 2b). Immunostaining also indicated that there was a significant increase in p-Stat 3 nuclear localization in the luminal epithelium of the ActD-treated mice on days 8 and 9 (Fig. 2c). When the cultured luminal epithelial cells were treated with different concentrations of ActD, the levels of both Lif mRNA and p-Stat3 protein were significantly increased (Fig. 2d, e). These results suggest that the Lif-STAT3 signaling pathway should be activated by ActD treatment in the mouse uterus.

\section{Effects of ActD-soaked beads on embryo implantation}

Because we showed that delayed implantation was activated by ActD, ActD-soaked beads were used to analyze the effects of nucleolar stress on embryo implantation. When ActD-soaked beads $(1 \mathrm{mM})$ were transferred into the uterine lumen on day 4 of pseudopregnancy, these beads were very effective in inducing a blue reaction (blue bands) on day 6 (Fig. 3a). Compared to the effects in the control mice, the treatment of mice with ActD-soaked beads caused a translocation of NPM1 from the nucleolus to the nucleoplasm in the luminal epithelial cells around the beads (Fig. 3b). In ActD-treated uteri, there was an obvious induction of Ptgs2, Wnt4 and Egr1 mRNA expression in the stroma surrounding the beads, which expression patterns were similar to the implantation sites of day 5 of pregnancy (Fig. 3c). These results suggest that nucleolar stress could induce an implantation-like reaction and an implantation-related gene expression pattern.

\section{Nucleolar stress during natural embryo implantation}

Because our data suggested that nucleolar stress is closely related to embryo implantation, we aimed to explore 
A

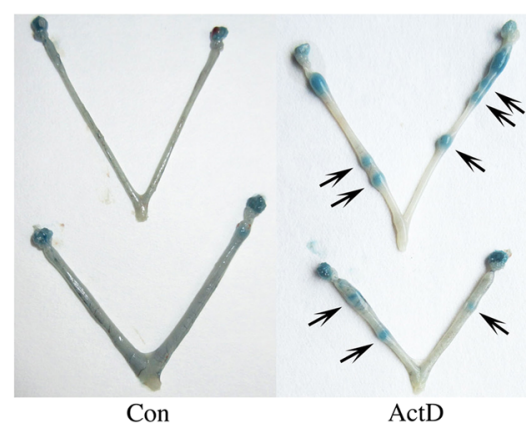

B

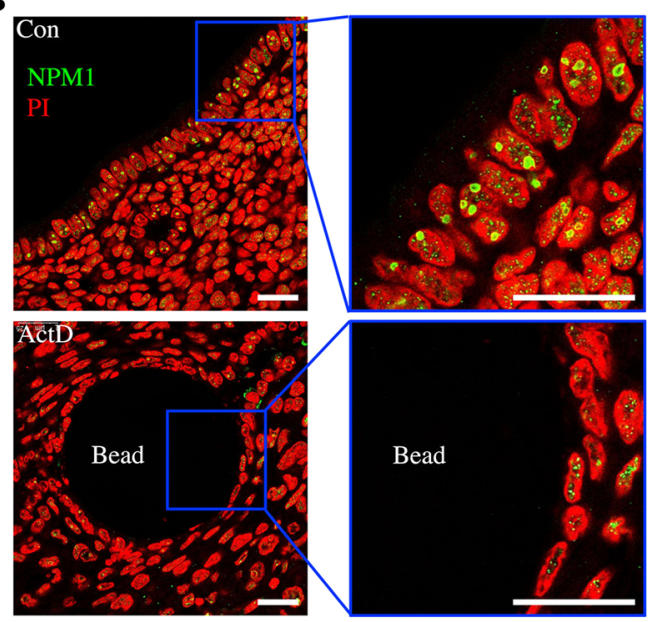

C

D5-NI

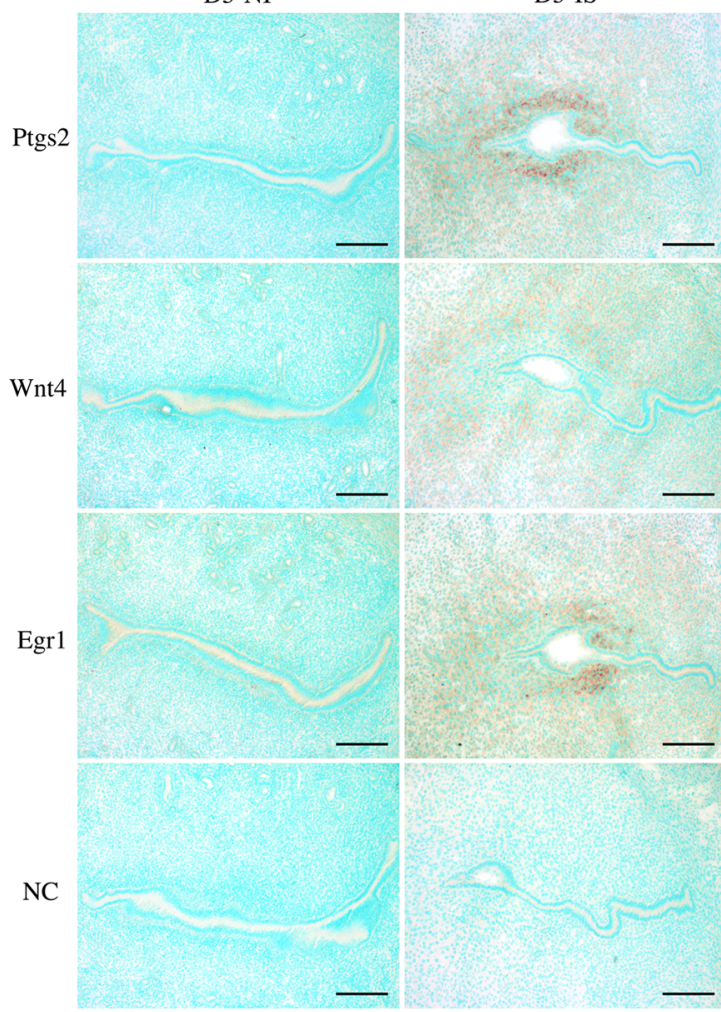

Con
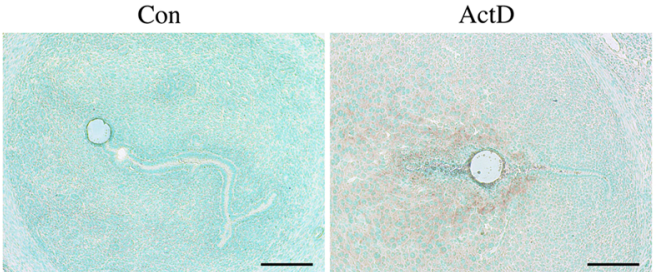
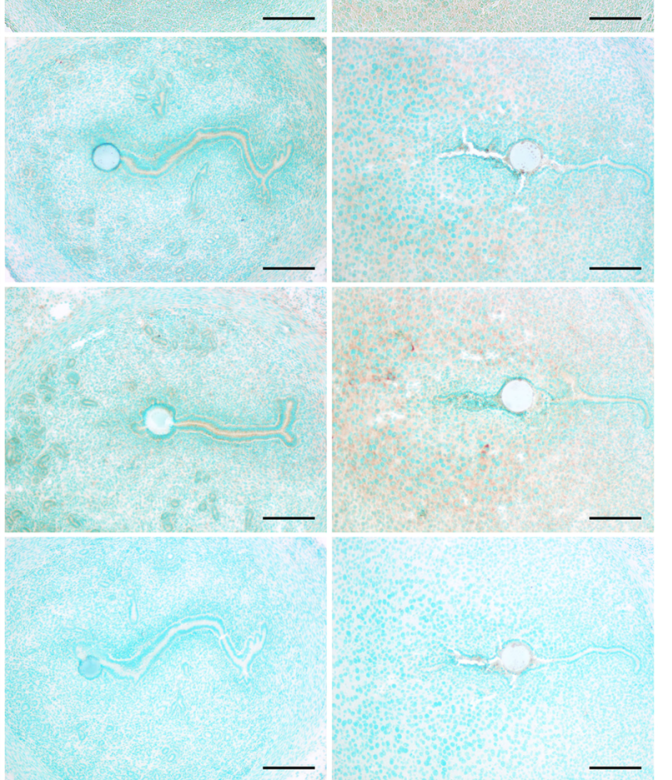

Fig. 3 The effects of ActD-soaked beads on the attachment reaction in the mouse uterus. a The blue bands in the mouse uteri on day 6 after ActD (1 mM)-soaked beads were transplanted into the uteri of pseudopregnant mice on day 4. b NPM1 immunofluorescence after the transfer of ActD-soaked beads (right image, enlarged from the blue quadrate in the left image). Bar $=25 \mu \mathrm{m}$. c In situ hybridization of the Ptgs2, Wnt4 and Egr1 mRNA after the transfer of the ActD-soaked beads and day 5 of pregnancy. Bar $=100 \mu \mathrm{m}$

whether nucleolar stress was present during natural embryo implantation. On day 4 of pregnancy, NPM1 signals were mainly located in the nucleoli of endometrial cells. On day 5 of pregnancy, NPM1 signals were significantly decreased in the nucleoli of the luminal epithelium at the implantation sites, while NPM1 signals were also observed in the nucleoli at the inter-implantation sites (Fig. 4a). Compared to those of the inter-implantation sites, the protein and mRNA expression levels of p53 were obviously increased at the implantation sites on day 5 (Fig. 4b, c). These results suggest that nucleolar stress should exist during embryo implantation. 


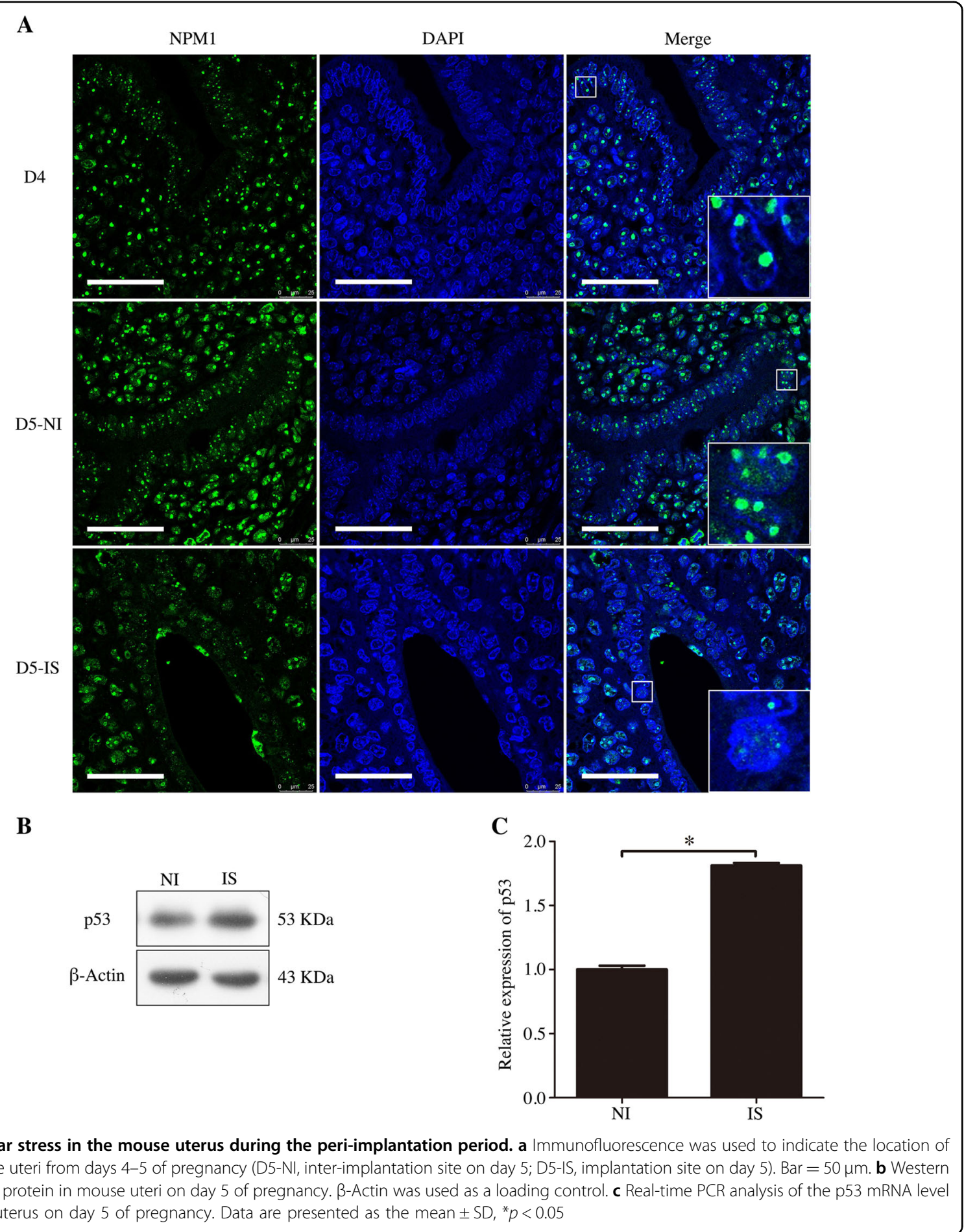

\section{Blastocyst-derived lactate induces nucleolar stress in} luminal epithelial cells

Our data showed that nucleolar stress exists during mouse embryo implantation. We wondered what initiates nucleolar stress during early pregnancy. TNF $\alpha$ is expressed and secreted from blastocysts ${ }^{11,29}$. However, TNF $\alpha$ treatment from 3 to $24 \mathrm{~h}$ had no effects on the translocation of
NPM1 in the nucleolus (Fig. 5a) (the data of $3 \mathrm{~h}, 12 \mathrm{~h}$, and $24 \mathrm{~h}$ were not shown). In mice, uterine acidification occurs during embryo implantation ${ }^{30}$. In human fertile endometrial fluid, Lactobacillus is the dominated microbiota ${ }^{31}$. Additionally, blastocysts can secrete lactate into the surrounding fluids during development ${ }^{32}$. Thus, we assumed that lactate may be involved in uterine acidification. In our 


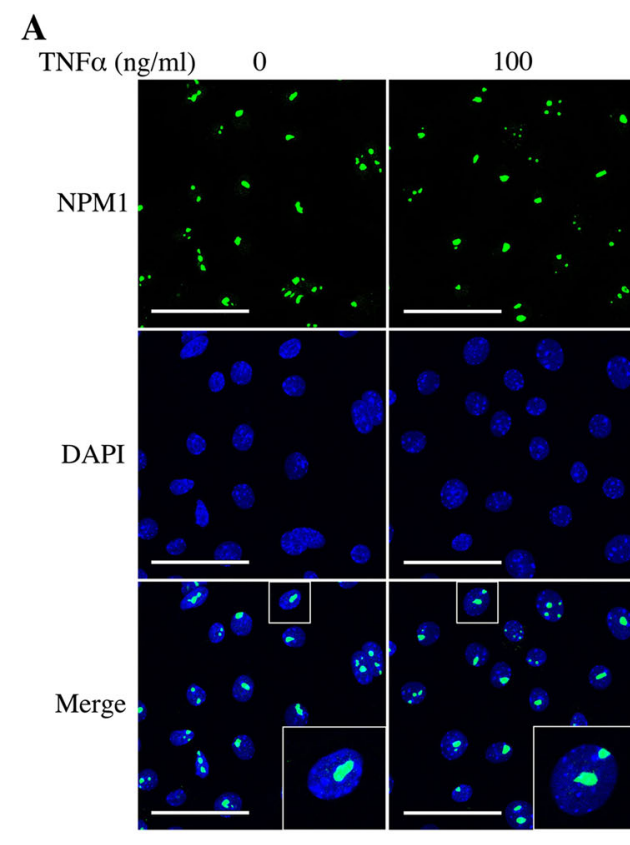

B

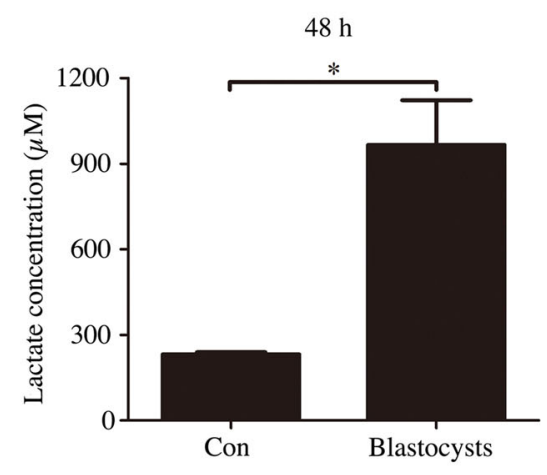

D

C
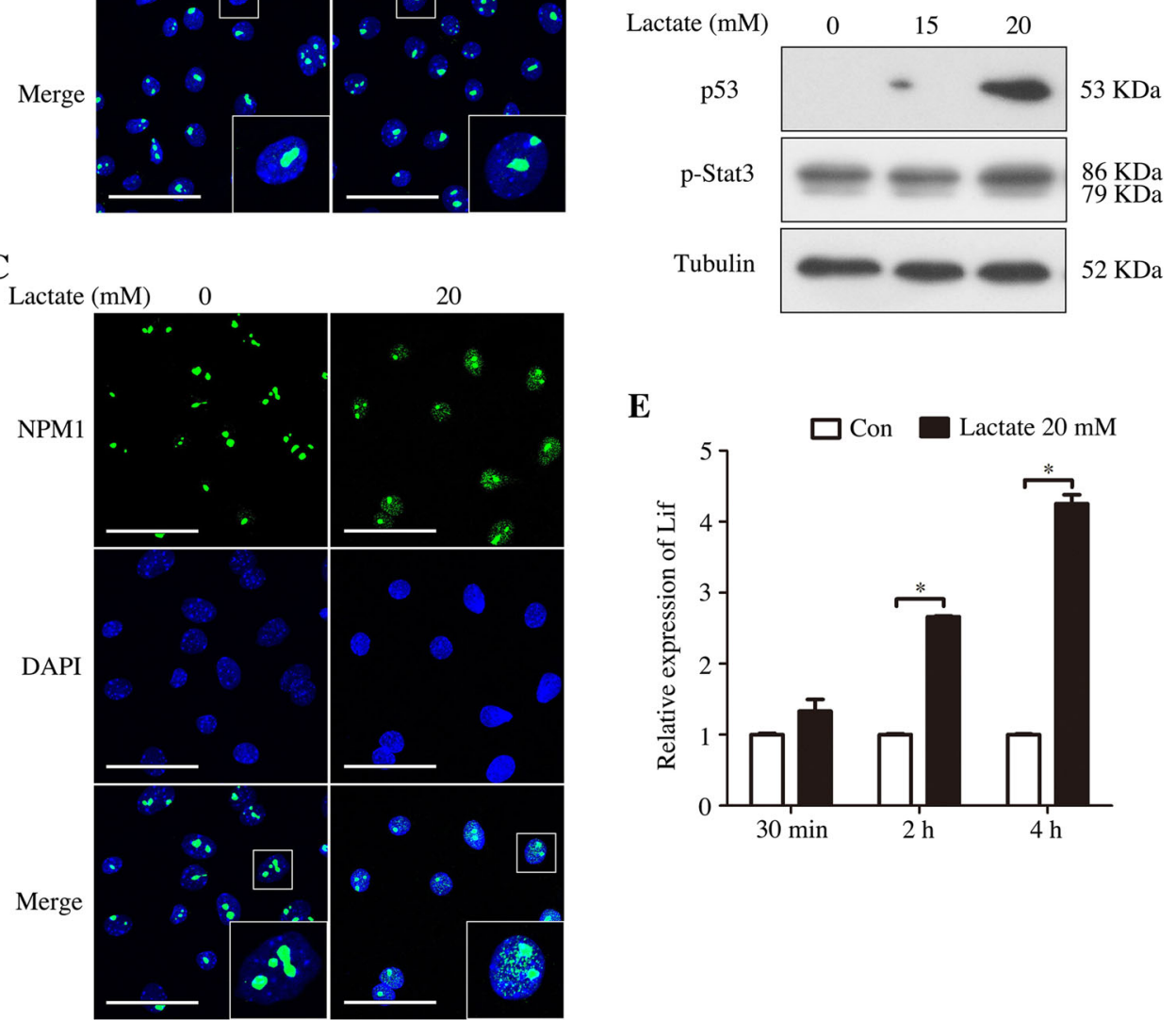

$\mathbf{E}$

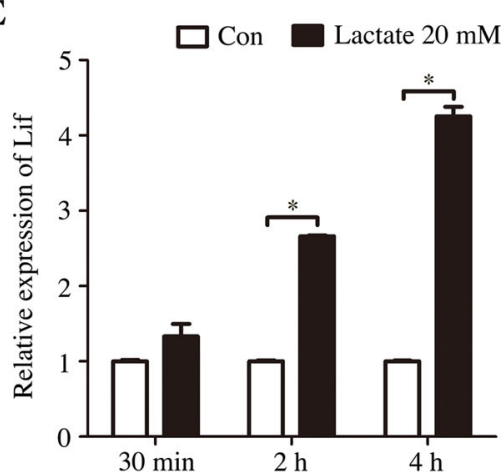

Fig. 5 Induction of nucleolar stress in uterine luminal epithelial cells. a The location of NPM1 in the luminal epithelial cells treated with $100 \mathrm{ng} /$ $\mathrm{ml}$ TNFa for $6 \mathrm{~h}$. Bar $=25 \mu \mathrm{m}$. b The lactate concentration changes of medium after embryos cultured for $48 \mathrm{~h}$. $\mathbf{c}$ The location of NPM1 in the luminal epithelial cells treated with $20 \mathrm{mM}$ lactate for $2 \mathrm{~h}$. Bar $=25 \mu \mathrm{m}$. d Western blot of the p53 and p-Stat3 proteins in the lactate-treated luminal epithelial cells. Tubulin was used as a loading control. e Real-time PCR analysis of the Lif mRNA level in the lactate-treated luminal epithelial cells. Data are presented as the mean $\pm \mathrm{SD},{ }^{*} p<0.05$

study, the concentration of lactate in the culture medium was increased after the blastocysts of day 4 were cultured for $48 \mathrm{~h}$ (Fig. 5b). Therefore, we further analyzed the effects of lactate on nucleolar stress. When cultured epithelial cells were treated with $20 \mathrm{mM}$ lactate for $2 \mathrm{~h}$, NPM1 was partly relocated from the nucleolus to the nucleoplasm (Fig. 5c). Meanwhile, lactate treatment induced a significant increase in p53 and p-Stat3 (Fig. 5d). The expression of Lif mRNA was also upregulated by lactate treatment from $30 \mathrm{~min}$ to $4 \mathrm{~h}$ (Fig. 5e). These data suggested that nucleolar stress could be activated by lactate in the luminal epithelial cells. 

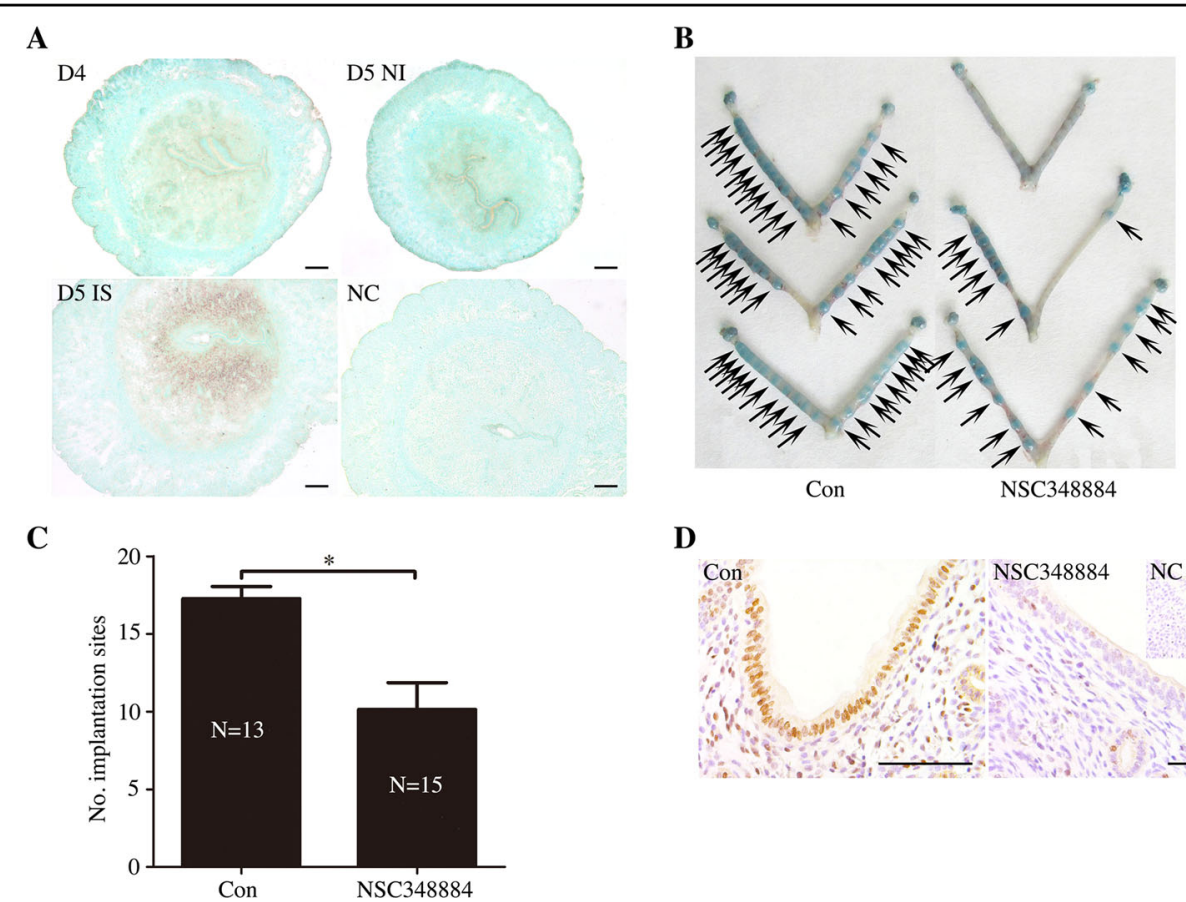

$\mathbf{D}$

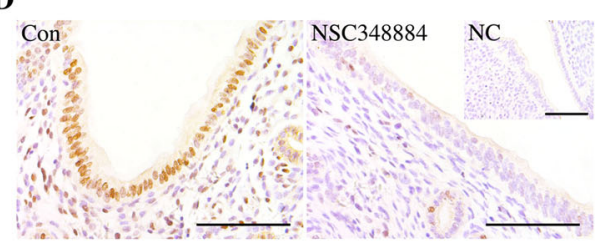

Fig. 6 Npm1 expression and function during embryo implantation. a In situ hybridization on the mRNA localization of NPM1 in mouse uteri from days $4-5$ of pregnancy. Bar $=100 \mu \mathrm{m}$. b The morphology of uteri on day 6 after the mice were treated with NSC348884 (160 $\mu \mathrm{g} / \mathrm{mouse})$ on days 4 and 5. c The mean number of implantation sites on day 6 under NSC348884 treatment ( $\mathrm{N}$, the number of mice). $\mathbf{d}$ Immunohistochemical staining was used to show the p-Stat3 protein in uteri on day 4 after the mice were treated with NSC348884 $(160 \mu \mathrm{g} / \mathrm{mouse})$ on day 3. Bar $=100 \mu \mathrm{m}$. Data are presented as the mean $\pm \mathrm{SD},{ }^{*} p<0.05$

The expression and function of NPM1 in the periimplantation uterus

The translocation of NPM1 in the nucleolus is a marker of nucleolar stress ${ }^{11,17}$. We would like to examine Npm1 expression in the mouse uterus. In situ hybridization showed that there was a basal level of Npm1 mRNA expression in the uterine endometrium on pregnancy day 4 and in the inter-implantation sites on pregnancy day 5 . Npm1 was strongly expressed in the decidual cells at the implantation sites on pregnancy day 5 (Fig. 6a).

NSC348884 is a specific inhibitor of NPM1 that disrupts NPM1 oligomer formation ${ }^{33}$. When pregnant mice were treated with NSC348884 from days 4 to 5 of pregnancy, the number of implantation sites was significantly reduced (Fig. 6b, c). Immunostaining experiments showed that the level of p-Stat3 nuclear localization in the luminal epithelial cells on day 4 was significantly decreased in NSC348884-treated mice (Fig. 6d). These results show that NPM1 is important for mouse embryo implantation.

\section{Nucleolar stress could be induced inAN3 CA cells by low- dose ActD}

To translate our mouse data into humans, we examined nucleolar stress in human endometrium. AN3 CA cells, a non-receptive human endometrium epithelial cell line, were treated by a low dose of ActD in the concentration of $0.1,1$, and $10 \mathrm{nM}$ for $48 \mathrm{~h}$, respectively. Results showed that ActD could inhibit pre-rRNA (ITS1) transcription (Fig. 7a) and promote p53 protein accumulation at the $10 \mathrm{nM}$ (Fig. 7b). Furthermore, $10 \mathrm{nM}$ ActD could give rise to dislocation of NPM1 protein from the nucleolar to the nucleoplasm (Fig. 7c). All of results above suggested that low-dose ActD did induce a significant nucleolar stress in AN3 CA.

\section{Effects of nucleolar stress on adhesivity of AN3 CA cells to trophoblast spheroids}

Embryo implantation can be induced by low-dose ActD in rats and mice ${ }^{18,19}$. Since nucleolar stress could be induced by low-dose ActD in human endometrium epithelial cell AN3 CA, it is very interesting to speculate whether nucleolar stress can promote human implantation in an in vitro embryo implantation model using AN3 CA and Jeg-3 spheroids co-culture system. Therefore, in present study, AN3 CA cells were treated with $10 \mathrm{nM}$ ActD for $48 \mathrm{~h}$ in which concentration is confirmed to elicit nucleolar stress in AN3 CA cells. The results suggested that compared to control, Jeg-3 spheroids attachment rates to AN3 CA monolayer were significantly upregulated by ActD treatment (Fig. 7d). 
A

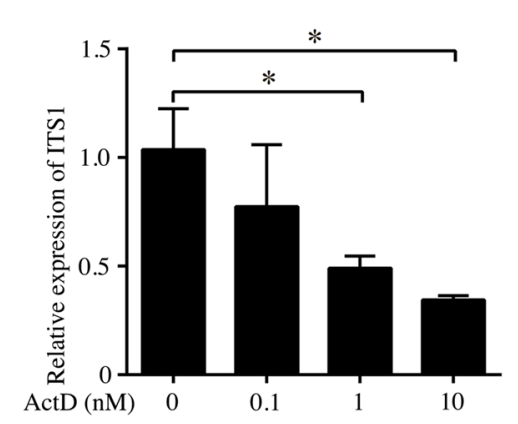

C

ActD (nM) NPM1

0
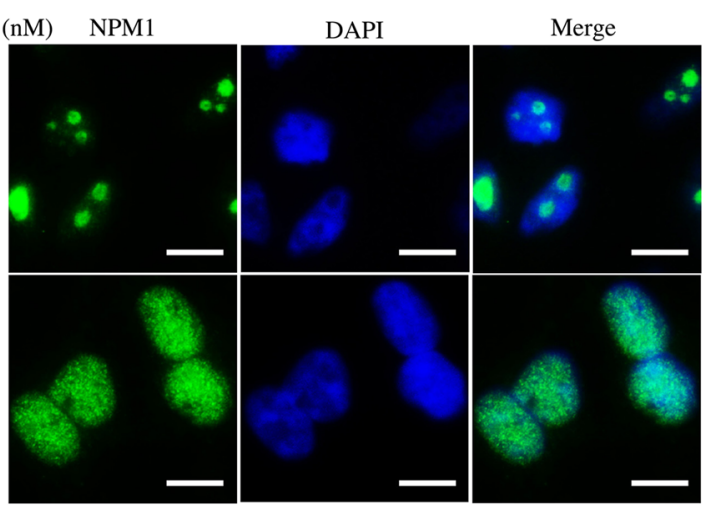

F

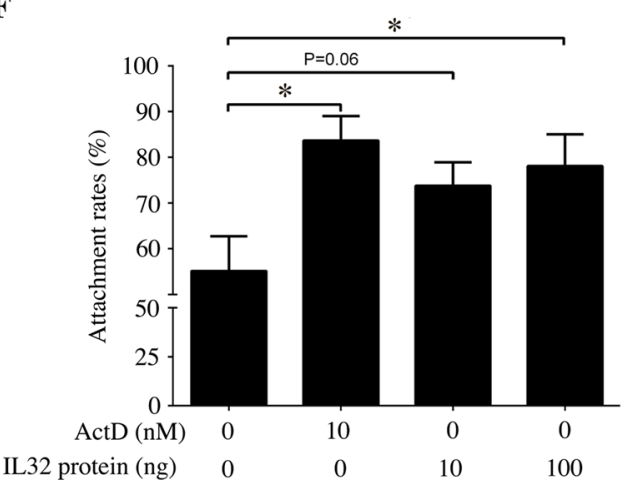

B

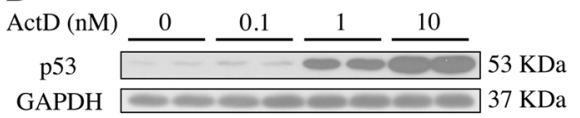

D

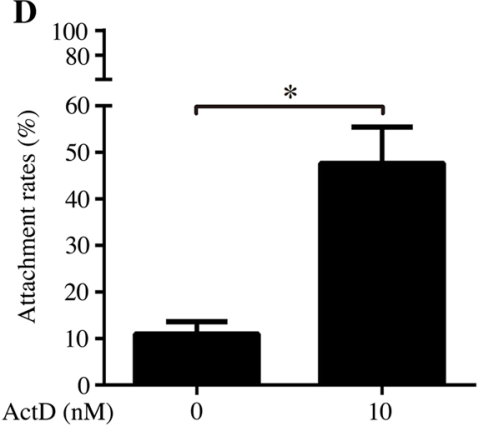

$\mathbf{E}$

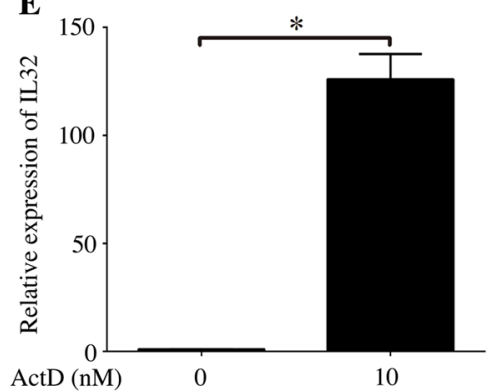

Fig. 7 Induction of nucleolar stress in AN3 CA cells and effects of IL32 on trophoblast spheroid attachment to monolayer AN3 CA cells in vitro. a Real-time PCR analysis of the ITS1 mRNA level in the ActD-treated AN3 CA cells. b Western blot of the p53 protein in ActD-treated AN3 CA cells. GAPDH was used as a loading control. c The location of NPM1 in the AN3 CA cells treated with ActD for $48 \mathrm{~h}$. Bar $=10 \mu \mathrm{m}$. $\mathbf{d}$ The rates of attached Jeg-3 spheroids to monolayer AN3 CA cells which are treated with $10 \mathrm{nM}$ ActD for $48 \mathrm{~h}$. e Real-time PCR analysis of the IL32 mRNA level in the ActD-treated AN3 CA cells. $\mathbf{f}$ The Jeg-3 spheroid attachment rates to AN3 CA treated with $10 \mathrm{nM}$ ActD or different concentration of IL $32 \mathrm{for} 48 \mathrm{~h}$. Data are presented as the mean $\pm \mathrm{SD},{ }^{*} p<0.05$

IL32 mediates the adhesion promotion effect of nucleolar stress on AN3 CA cell monolayer

In order to explore the mechanism by which ActD upregulates the Jeg-3 cell spheroids adhesion rates to AN3 CA monolayer, RNA-seq was performed in AN3 CA cells treated with ActD. The top 50 upregulated genes were listed, including IL32 (Table 2). IL32, a secretory adhesion molecular that could interact with the extracellular part of $\alpha \mathrm{V} \beta 3$ through RGD peptides ${ }^{34}$, was upregulated dramatically by ActD compared to control. The RNA-seq data were confirmed by real-time PCR. ActD could upregulate IL32 expression by more than 100 folds in AN3 CA cells (Fig. 7e). Based on the above results, it seems that it is IL32 that mediates the adhesion promoting effects of ActD. To ascertain the action of IL32, IL32 recombinant protein was introduced to analyze the effects of IL32 on the Jeg-3 spheroids attachment rates to AN3 CA cell monolayer. When AN3 CA cells were treated with $10 \mathrm{nM}$ ActD, $10 \mathrm{nM}$, or $100 \mathrm{nM} \mathrm{IL32,} \mathrm{the} \mathrm{attachment} \mathrm{rate} \mathrm{was}$ 
Table 2 The RNA-seq data

\begin{tabular}{|c|c|c|}
\hline Serial no. & Symbol & Log2 ratio(Act D/DMSO) \\
\hline 1 & GAGE5 & 13.63662462 \\
\hline 2 & NEDD8-MDP1 & 10.51569984 \\
\hline 3 & LOC554249 & 9.625708843 \\
\hline 4 & RPL17-C18orf32 & 9.027905997 \\
\hline 5 & FAM90A27P & 8.864186145 \\
\hline 6 & LOC100506860 & 8.707359132 \\
\hline 7 & LOC541473 & 8.535275377 \\
\hline 8 & ATP6V1G2-DDX39B & 8.535275377 \\
\hline 9 & GOLGA6L3 & 8.28077077 \\
\hline 10 & LOC100287834 & 7.95419631 \\
\hline 11 & HCST & 7.845490051 \\
\hline 12 & ARL2-SNX15 & 7.665335917 \\
\hline 13 & FABP5 & 7.426264755 \\
\hline 14 & TMEM31 & 7.330916878 \\
\hline 15 & RPL3L & 7.276124405 \\
\hline 16 & SYNJ2BP-COX16 & 7.257387843 \\
\hline 17 & LINC00854 & 7.21916852 \\
\hline 18 & ACP5 & 7.044394119 \\
\hline 19 & LIMS4 & 6.918863237 \\
\hline 20 & NPTX2 & 6.87036472 \\
\hline 21 & GALR2 & 6.804131021 \\
\hline 22 & LOC79999 & 6.741466986 \\
\hline 23 & PDLIM1 & 6.614709844 \\
\hline 24 & CDRT4 & 6.475733431 \\
\hline 25 & FRG2 & 6.475733431 \\
\hline 26 & HSD17B6 & 6.375039431 \\
\hline 27 & CLDN7 & 6.266786541 \\
\hline 28 & NHLH1 & 6.169925001 \\
\hline 29 & SENP3-EIF4A1 & 6.14974712 \\
\hline 30 & GIPC3 & 6 \\
\hline 31 & MPZ & 5.977279923 \\
\hline 32 & RNU6-1 & 5.94641896 \\
\hline 33 & $\mathrm{HCN} 4$ & 5.930737338 \\
\hline 34 & MYBPC3 & 5.930737338 \\
\hline 35 & STX16-NPEPL1 & 5.906890596 \\
\hline 36 & ST20-MTHFS & 5.700439718 \\
\hline 37 & ZNF559-ZNF177 & 5.672425342 \\
\hline 38 & FGR & 5.672425342 \\
\hline 39 & GGT8P & 5.339850003 \\
\hline
\end{tabular}

Table 2 continued

\begin{tabular}{lll}
\hline Serial no. & Symbol & Log2 ratio(Act D/DMSO) \\
\hline 40 & MUC22 & 5.247927513 \\
41 & ZNF582 & 5.087462841 \\
42 & LMTK3 & 5.087462841 \\
43 & IL32 & 5.069673528 \\
44 & ELAVL3 & 5.044394119 \\
45 & LOC286059 & 4.977279923 \\
46 & CEND1 & 4.727584358 \\
47 & PDGFRA & 4.700439718 \\
48 & CDC42BPG & 4.64385619 \\
49 & COL1A1 & 4.64385619 \\
50 & PLK2 & 4.558368291 \\
\hline
\end{tabular}

significantly upregulated by $100 \mathrm{nM}$ IL32 compared with control, in common with $10 \mathrm{nM}$ ActD (Fig. 7f).

\section{The effects of nucleolar stress on human endometrium epithelial cells with unequal receptivity}

Our data showed that nucleolar stress is beneficial for the adhesion of AN3 CA. Because AN3 CA cell is a nonreceptive cell line, we explored whether data from AN3 CA cells could be applied to receptive cell lines. Ishikawa cell line is a well-differentiated steroid-responsive endometrial cell line with characteristics of luminal epithelium and glandular epithelium which represent a receptive endometrium $^{35}$. When Ishikawa cells were treated with ActD for $48 \mathrm{~h}$, ITS1 transcription was reduced (Fig. 8a), followed by an increase of p53 protein (Fig. 8b) and NPM1 translocation from the nucleolus to the nucleoplasm (Fig. 8c). However, ActD-induced nucleolar stress had no effects on the adhesivity of Ishikawa monolayer to trophoblast spheroids (Fig. 8d). Because IL32 was shown to mediate the adhesive effect of nucleolar stress on AN3 CA, we checked the level of IL32 expression in Ishikawa cell line. After Ishikawa cells were treated with ActD, IL32 expression increased, but only around 2-folds in Ishikawa cells by nucleolar stress (Fig. 8e).

\section{The NPM1 expression in human endometrium during menstrual cycle}

Because NPM1 is a multi-functional chaperone in nucleolus and plays crucial roles in nucleolar stress response $^{11}$. We examined NPM1 expression pattern in human endometrium. Results demonstrated that NPM1 protein expression was detected in human endometrium during the menstrual cycle, showing a gradual increasing manner from proliferation phase to late secretory phase, especially highly expressed in luminal epithelium (Supplemental Fig. S1). 

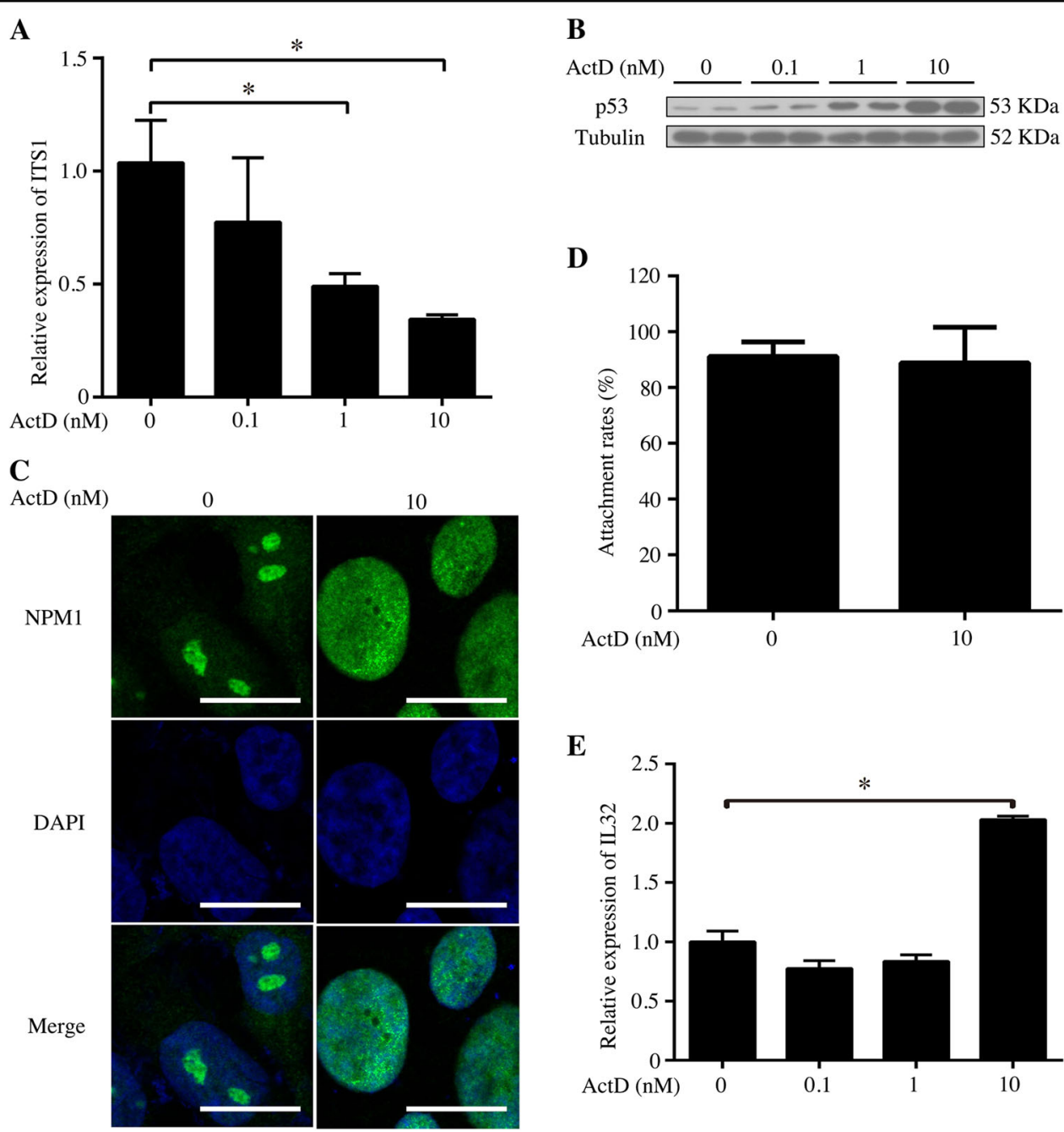

D

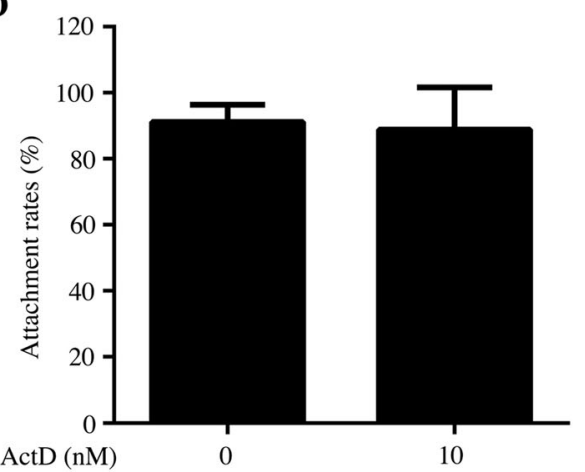

$\mathbf{E}$

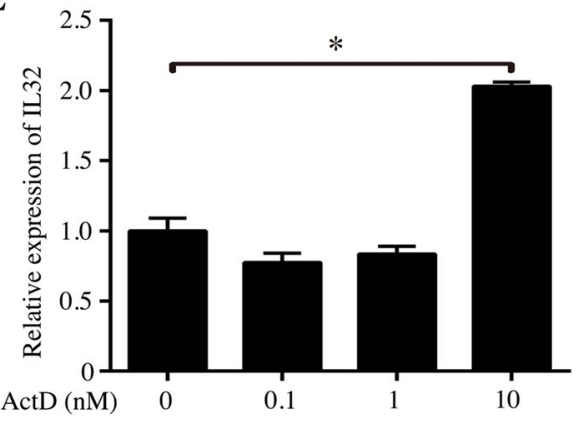

Fig. 8 The effects of nucleolar stress on the human Ishikawa epithelial cells. a Real-time PCR analysis of ITS1 mRNA level in the ActD-treated Ishikawa cells. b Western blot of the p53 protein in ActD-treated Ishikawa cells. Tubulin was used as a loading control. c The location of NPM1 in the Ishikawa cells treated with ActD for $48 \mathrm{~h}$. Bar $=10 \mu \mathrm{m}$. d The rates of attached Jeg-3 spheroids to monolayer Ishikawa cells which are treated with $10 \mathrm{nM}$ ActD for $48 \mathrm{~h}$. e Real-time PCR analysis of the IL32 mRNA level in the ActD-treated Ishikawa cells. Data are presented as the mean \pm SD, ${ }^{*} p<0.05$

\section{Discussion}

Previous studies have demonstrated that the delayed implantation of mice and rats can be activated by $\mathrm{ActD}^{18,19}$. However, the underlying mechanism was unclear. In this study, we show that delayed implantation can be activated by ActD-induced nucleolar stress. To our knowledge, this should be the first study to demonstrate that nucleolar stress plays a key role during embryo implantation.

NPM1 is located in the nucleoli of cells under normal conditions. During nucleolar stress, NPM1 relocates from the nucleolus to the nucleoplasm ${ }^{11,17}$. In the nucleoplasm, NPM1 can combine with Mdm2 and prevent it from degrading p53, resulting in p53 accumulation ${ }^{8}$. Therefore, the relocation of NPM1 from the nucleolus to the nucleoplasm and p53 accumulation are two hallmark events of nucleolar stress ${ }^{11,17}$. In our study, both NPM1 translocation and p53 accumulation were detected in the luminal epithelium at implantation sites on day 5 of pregnancy and during the activation of delayed implantation. We also found that both Lif mRNA and p-Stat3 protein levels were upregulated by ActD. In mice, p53 (the upstream of the Lif-STAT3 signaling pathway) is essential for the establishment of uterine receptivity ${ }^{14,16}$. p53 deficiency in $\mathrm{C} 57$ background mice results in a reduction in embryo implantation and pregnancy rate, which can be rescued by the administration of LIF $^{16}$. Maternal Lif is strongly expressed in the glandular epithelium and is required for mouse embryo implantation ${ }^{13}$. The conditional knockout of uterine Stat3 also causes an embryo 
implantation failure ${ }^{14,15}$. In our study, ActD-soaked beads also initiated an implantation reaction in the mouse uterus and upregulated the levels of both Lif mRNA and p-Stat3 protein. To our knowledge, our data are the first to demonstrate that ActD-induced nucleolar stress is present during early pregnancy and plays a key role in embryo implantation.

The dialog between the blastocyst and the receptive uterus is essential for successful implantation ${ }^{1}$. Lactate is a main product of glycolysis $^{36,37}$. Monocarboxylate transporters (Mct) facilitate the transport of lactate between the extracellular and intracellular environments ${ }^{32}$. Mct4, a lactate exporter, is expressed in the mouse blastocyst ${ }^{38}$. The blastocyst can secrete lactate into the surrounding fluids during development. Lactate may be related to uterine acidification during embryo implantation $^{32}$. Our data also indicate that lactate has a time-dependent induction of Lif expression in luminal epithelial cells. Additionally, the nucleolar stress in the luminal epithelial cells is induced by lactate. Therefore, our data suggest that blastocyst-secreted lactate may induce nucleolar stress in the luminal epithelial cells, which should be important for embryo implantation.

NPM1 is a nucleolar phosphoprotein that localizes in the granular regions of the nucleolus ${ }^{39}$. The function of NPM1 requires dimer and pentamer formation by oligomerization $^{33}$. NPM1 oligomerization can effectively activate STAT3 ${ }^{40}$. In our study, Npm1 is strongly expressed in the primary decidua at implantation sites. When pregnant mice are treated with NSC348884, a specific inhibitor of $\mathrm{NPM}^{33}$, the number of implantation sites is obviously inhibited. The level of p-Stat3 nuclear localization in the uterine luminal epithelium on day 4 of early pregnancy is also suppressed by NSC348884. Therefore, our data imply that NPM1 may play a key role during embryo implantation via nucleolar stress.

Although human embryo implantation cannot be studied in vivo due to ethical limitation, accumulating evidences validate the reliability and reproducibility of in vitro co-culture model of embryo-endometrial attachment in previously published studies ${ }^{41,42}$. The present study demonstrated that in vitro treatment with ActD has a significant promoting effect on embryo-endometrial attachment in a Jeg-3 spherods-AN3 CA cell co-culture model. However, this adhesion-promoting effect is not demonstrated within Jeg-3 spheroids-Ishikawa co-culture system. These results suggested that high-receptive epithelial cells (Ishikawa) are less sensitive than low receptivity epithelial cells (AN3 CA) to nucleolar stress induced by low dose of ActD. The nucleolar stress activated by canonical inducer, such as low dose of ActD, may have a beneficial effect on patients with poor endometrium receptivity which is the leading cause of female infertility, including recurrent implantation failure ${ }^{43,44}$.
Furthermore, the increasing evidence demonstrates that an improvement in implantation rates or clinical pregnancy rate was showed in patients with a history of recurrent pregnancy loss or unexplained miscarriage who received endometrial scratch injury ${ }^{45,46}$. A similarity between nucleolar stress and endometrial scratch injury is that they are both effective only in patients with poor endometrium receptivity. Accordingly, it is postulated that there may have some inner relations between endometrial scratch injury and nucleolar stress response which is worthy of further investigation. Notwithstanding, the data gained from in vitro cell culture models could not be directly introduced to human beings. In view of unavailability of actual human blastocysts for such experimental use due to ethical reason, the present study may, more or less, shed a light on the remedy of recurrent implantation failure patients with low endometrium receptivity.

In our study, data from transcriptomic sequencing indicated that there are 380 upregulated genes with at least 4 folds in ActD-treated group compared to control. Among the upregulated genes, IL32 is one of the top 50 upregulated genes (Table 2). IL32 is a proinflammatory cytokine that could be secreted ${ }^{47}$. Besides, IL32 contains an RGD motif which interacts with the extracellular domain of integrins including $\alpha \mathrm{V} \beta 3$ and $\alpha \mathrm{V} \beta 6$ integrins ${ }^{34}$. Therefore, IL32 is selected as a candidate that mediates the adhesion promoting effects of nucleolar stress on the co-culture system of Jeg-3 spheroids and AN3 CA cell monolayer. Increasing evidence demonstrates that IL32 has a positive effect on invasion and migration in breast cancer cells and human gastric cancer cells ${ }^{48,49}$.

There are plenty of immunology accommodation and inflammatory reaction existing during embryo implantation. Stress response may exist in the normal physiological process and play essential parts in embryo implantation if these stress responses are fine-tuned. We previously demonstrated that a proper endoplasmic reticulum stress is important for mouse embryo implantation ${ }^{21}$. In present study, nucleolar stress is induced successfully by ActD in Ishikawa and AN3 CA which are on behalf of highreceptive and low-receptive human endometrium epithelial cells, respectively. Nucleolar stress has a positive effect on embryo implantation in a widely used human in vitro implantation model. Moreover, the important nucleolar stress effector NPM1 is highly expressed in the mid- or late secretory human endometrium, especially in lumen epithelial cell nucleolus. These data suggested that physiological nucleolar stress response may play positive roles in human implantation process.

In summary, our data indicate that lactate-induced nucleolar stress may regulate mouse embryo implantation through the p53-Lif-STAT3 pathway. The localized NPM1 expression at implantation sites should be important for embryo implantation via mediating 
nucleolar stress. Furthermore, nucleolar stress may play a positive role in human embryo adhesion to endometrial epithelial cell monolayer through IL32.

\section{Acknowledgements}

This work was supported by National Key Research and Development Program of China (2018YFC1004403), National Natural Science Foundation of China (31471397, 31272263, and 31671563), and Science Research Start-up Fund for Doctor of Shanxi Medical University (XD1828).

\section{Author details}

'College of Veterinary Medicine, South China Agricultural University, 510642 Guangzhou, China. ${ }^{2}$ Laboratory Animal Center, Shanxi Key Laboratory of Experimental Animal Science and Animal Model of Human Disease, Shanxi Medical University, 030001 Taiyuan, China. ${ }^{3}$ Shanxi Key Laboratory of Birth Defect and Cell Regeneration, Shanxi Medical University, 030001 Taiyuan, China. ${ }^{4}$ Reproductive Medicine Center, Renmin Hospital, Hubei University of Medicine, 442000 Shiyan, China. ${ }^{5}$ Jiangxi Provincial Institute of Occupational Medicine, 330006 Nanchang, China

\section{Conflict of interest}

The authors declare no competing interests.

\section{Publisher's note}

Springer Nature remains neutral with regard to jurisdictional claims in published maps and institutional affiliations.

Supplementary Information accompanies this paper at (https://doi.org/ 10.1038/s41419-019-2071-6).

Received: 26 June 2019 Revised: 20 September 2019 Accepted: 16 October 2019

Published online: 04 November 2019

\section{References}

1. Wang, H. \& Dey, S. K. Roadmap to embryo implantation: clues from mouse models. Nat. Rev. Genet. 7, 185-199 (2006).

2. Dey, S. K. et al. Molecular cues to implantation. Endocr. Rev. 25, 341-373 (2004).

3. Cha, J., Sun, X. \& Dey, S. K. Mechanisms of implantation: strategies for successful pregnancy. Nat. Med. 18, 1754-1767 (2012).

4. James, A., Wang, Y., Raje, H., Rosby, R. \& DiMario, P. Nucleolar stress with and without p53. Nucleus 5, 402-426 (2014).

5. Boisvert, F. M., van Koningsbruggen, S., Navascues, J. \& Lamond, A. I. The multifunctional nucleolus. Nat. Rev. Mol. Cell Biol. 8, 574-585 (2007).

6. Suzuki, A. et al. A new PICTure of nucleolar stress. Cancer Sci. 103, 632-637 (2012).

7. Bywater, M. J. et al. Inhibition of RNA polymerase I as a therapeutic strategy to promote cancer-specific activation of p53. Cancer Cell 22, 51-65 (2012).

8. Kurki, S. et al. Nucleolar protein NPM interacts with HDM2 and protects tumor suppressor protein p53 from HDM2-mediated degradation. Cancer Cell 5, 465-475 (2004).

9. Boulon, S., Westman, B. J., Hutten, S., Boisvert, F. \& Lamond, A. I. The nucleolus under stress. Mol. Cell 40, 216-227 (2010).

10. Lindstrom, M. S. NPM1/B23: a multifunctional chaperone in ribosome biogenesis and chromatin remodeling. Biochem. Res. Int. 2011, 195209 (2011).

11. Yang, K. et al. A redox mechanism underlying nucleolar stress sensing by nucleophosmin. Nat. Commun. 7, 13599 (2016).

12. Patsialou, A. et al. Selective gene-expression profiling of migratory tumor cells in vivo predicts clinical outcome in breast cancer patients. Breast Cancer Res. 14, R139-R139 (2012).

13. Stewart, C. L. et al. Blastocyst implantation depends on maternal expression of leukaemia inhibitory factor. Nature 359, 76-79 (1992).

14. Pawar, S. et al. STAT3 regulates uterine epithelial remodeling and epithelialstromal crosstalk during implantation. Mol. Endocrinol. 27, 1996-2012 (2013).
15. Sun, X., Bartos, A., Whitsett, J. A. \& Dey, S. K. Uterine deletion of Gp130 or Stat3 shows implantation failure with increased estrogenic responses. Mol. Endocrinol. 27, 1492-1501 (2013).

16. Hu, W., Feng, Z., Teresky, A. K. \& Levine, A. J. p53 regulates maternal reproduction through LIF. Nature 450, 721-724 (2007).

17. Avitabile, D. et al. Nucleolar stress is an early response to myocardial damage involving nucleolar proteins nucleostemin and nucleophosmin. Proc. Natl Acad. Sci. USA 108, 6145-6150 (2011).

18. Finn, C. A. \& Downie, J. M. Changes in the endometrium of mice after the induction of implantation by actinomycin D. J. Endocrinol. 65, 259-264 (1975).

19. Camus, M., Lejeune, B. \& Leroy, F. Induction of implantation in the rat by intraparametrial injection of actinomycin D. Biol. Reprod. 20, 1115-1118 (1979).

20. Yockey, L. J. \& Iwasaki, A. Interferons and proinflammatory cytokines in pregnancy and fetal development. Immunity 49, 397-412 (2018).

21. Gu, X. W. et al. Endoplasmic reticulum stress in mouse decidua during early pregnancy. Mol. Cell Endocrinol. 434, 48-56 (2016).

22. Liang, X. et al. Egr1 protein acts downstream of estrogen-leukemia inhibitory factor (LIF)-STAT3 pathway and plays a role during implantation through targeting Wnt4. J. Biol. Chem. 289, 23534-23545 (2014).

23. De Clercq, K., Hennes, A. \& Vriens, J. Isolation of mouse endometrial epithelial and stromal cells for in vitro decidualization. J. Vis. Exp. 55168 (2017). https:// doi.org/10.3791/55168

24. $L i, H$. et al. Effect of ulipristal acetate and mifepristone at emergency contraception dose on the embryo-endometrial attachment using an in vitro human trophoblastic spheroid and endometrial cell co-culture model. Hum. Reprod. 32, 2414-2422 (2017).

25. Liu, J. et al. HB-EGF regulates Prss56 expression during mouse decidualization via EGFR/ERK/EGR2 signaling pathway. J. Endocrinol. 234, 247-254 (2017).

26. Paria, B. C. et al. Cellular and molecular responses of the uterus to embryo implantation can be elicited by locally applied growth factors. Proc. Natl Acad. Sci. USA 98, 1047-1052 (2001).

27. Ding, N. Z. et al. De novo synthesis of sphingolipids is essential for decidualization in mice. Theriogenology 106, 227-236 (2018).

28. Li, S. Y. et al. Impaired receptivity and decidualization in DHEA-induced PCOS mice. Sci. Rep. 6, 38134 (2016)

29. Tu, Z. et al. Uterine RAC1 via Pak1-ERM signaling directs normal luminal epithelial integrity conducive to on-time embryo implantation in mice. Cell Death Differ. 23, 169-181 (2016).

30. Xiao, S. et al. Acidification of uterine epithelium during embryo implantation in mice. Biol. Reprod. 96, 232-243 (2017).

31. Moreno, l. et al. Evidence that the endometrial microbiota has an effect on implantation success or failure. Am. J. Obstet. Gynecol. 215, 684-703 (2016).

32. Gardner, D. K. Lactate production by the mammalian blastocyst: Manipulating the microenvironment for uterine implantation and invasion? BioEssays 37, 364-371 (2015).

33. Qi, W. et al. NSC348884, a nucleophosmin inhibitor disrupts oligomer formation and induces apoptosis in human cancer cells. Oncogene 27, 4210-4220 (2008).

34. Heinhuis, B. et al. Interleukin 32 (IL-32) contains a typical alpha-helix bundle structure that resembles focal adhesion targeting region of focal adhesion kinase-1. J. Biol. Chem. 287, 5733-5743 (2012).

35. Hannan, N. J., Paiva, P., Dimitriadis, E. \& Salamonsen, L. A. Models for study of human embryo implantation: choice of cell lines? Biol. Reprod. 82, 235-245 (2010).

36. Robergs, R. A., Ghiasvand, F. \& Parker, D. Biochemistry of exercise-induced metabolic acidosis. Am. J. Physiol. Regul. Integr. Comp. Physiol. 287, R502-516 (2004).

37. Robergs, R. A., McNulty, C. R., Minett, G. M., Holland, J. \& Trajano, G. Lactate, not lactic acid, is produced by cellular cytosolic energy catabolism. Physiology 33, 10-12 (2018)

38. Zuo, R. et al. Warburg-like glycolysis and lactate shuttle in mouse decidua during early pregnancy. J. Biol. Chem. 290, 21280-21291 (2015).

39. Borer, R. A., Lehner, C. F., Eppenberger, H. M. \& Nigg, E. A. Major nucleolar proteins shuttle between nucleus and cytoplasm. Cell 56, 379-390 (1989).

40. Chang, T. P. et al. Tumor suppressor HU1 binds and functionally alters nucleophosmin via activating enhancer binding protein 2 complex formation. Cancer Res. 70, 1656-1667 (2010).

41. Berger, C., Boggavarapu, N. R., Menezes, J., Lalitkumar, P. G. L. \& GemzellDanielsson, K. Effects of ulipristal acetate on human embryo attachment and endometrial cell gene expression in an in vitro co-culture system. Hum. Reprod. 30, 800-811 (2015). 
42. Kodithuwakku, S. P. et al. Hormonal regulation of endometrial olfactomedin expression and its suppressive effect on spheroid attachment onto endometrial epithelial cells. Hum. Reprod. 26, 167-175 (2011).

43. Kim, T. H. et al. Loss of HDAC3 results in nonreceptive endometrium and female infertility. Sci. Transl. Med. 11, eaaf7533 (2019).

44. Sebastian-Leon, P. Garrido, N., Remohí, J., Pellicer, A. \& Diaz-Gimeno, P. Asynchronous and pathological windows of implantation: two causes of recurrent implantation failure. Hum. Reprod. 33, 626-635 (2018).

45. Sar-Shalom, N. C., Sagi-Dain, L., Wiener-Megnazi, Z. \& Dirnfeld, M. The impact of intentional endometrial injury on reproductive outcomes: a systematic review and meta-analysis. Hum. Reprod. Update 25, 95-113 (2019).
46. Vitagliano, A. et al. Endometrial scratch injury before intrauterine insemination: is it time to re-evaluate its value? Evidence from a systematic review and meta-analysis of randomized controlled trials. Fertil. Steril. 109, 84-96.e4 (2018).

47. Heinhuis, B. et al. Inflammation-dependent secretion and splicing of IL-32y in rheumatoid arthritis. Proc. Natl Acad. Sci. USA 108, 4962-4967 (2011).

48. Sloot, Y., Smit, J. W., Joosten, L. \& Netea-Maier, R. T. Insights into the role of IL32 in cancer. Semin. Immunol. 38, 24-32 (2018).

49. Tsai, C. Y. et al. Interleukin-32 increases human gastric cancer cell invasion associated with tumor progression and metastasis. Clin. Cancer Res. 20, 2276-2288 (2014) 